\title{
Seedling morphology of different wheat genotypes at early stages under hydrocultural conditions
}

\author{
László Zsombik - Alexandra Hanász - Tamás Sipos - Oqba Basal - Katalin Magyar-Tábori \\ University of Debrecen, Research Institutes and Study Farm, Research Institute of Nyíregyháza \\ oqbabasal@gmail.com
}

\begin{abstract}
SUMMARY
Consuming "sprouted seeds" is one of the most important factors of a healthy diet. An experiment was conducted in the University of Debrecen, Research Centre of Nyiregyháza (Hungary) in 2014 to analyse some morphological traits of four winter wheat genotypes (Triticum aestivum L.) and one spelt (T. spelta) variety. Our results showed that the spelt wheat variety "Franckenkorn" could maintain higher root length throughout the experimental period. On average, both "Perbetei" and "Franckenkorn" varieties could maintain higher root number compared to the other varieties. The extensive breeding line "1401 HK" had the highest shoot length throughout the whole experiment, being significantly higher than the landrace variety "Perbetei" and both of the varieties "KG Bendegúz" and "KG Kunhalom". It could be concluded that "KG Bendegúz" cultivar and "Perbetei" landrace seem to be the most suitable for aquaculture techniques. In addition, "1401 HK" breeding line can be the most suitable for the production of juice since the minimal required shoot length $(12 \mathrm{~cm})$ was achieved within the shortest period of time after sowing (9 days). This breeding line and "Franckenkorn" can also be suitable for production of "wheatgrass", because it is consumed without roots. Further research is needed to evaluate nutritional values of these genotypes.
\end{abstract}

Keywords: aquaculture; shoot and root parameters; Triticum aestivum; Triticum spelta

\section{INTRODUCTION}

The consumption of "sprouted seeds" as a food is becoming increasingly important in a healthy diet. In addition to fresh consumption ("ready-to-eat" sprouts), they are also present in the market as a processed product (dried or toasted). The final product for consumption may be different depending on the method of production and the plant parts to be consumed (with or without seeds, roots or young leaves/cotyledons) (Benincasa et al., 2019); for example, the "wheatgrass" means the shoots of the 610-day old wheat seedlings (Pant et al., 2013).

The nutritional value of wheatgrass is given by the easily accessible essential trace elements (Kulkarni et al., 2007) and high antioxidant content, which reaches its peak on about $7^{\text {th }}-8^{\text {th }}$ day of growing (Kulkarni et al., 2006). Peptides and amino acids also increase its nutritional value. The way of production is often aquaculture, which is also suitable for the production of fodder (Benincasa et al., 2019; Ndaru et al., 2020).

The hydroponic cultivation conditions are also suitable for performing various laboratory tests. For example, hydroculture experiments can be used for the evaluation of stress tolerance capacity (Ashraf and Ashraf, 2016; Rizwan et al., 2016), and the colonization capacity of roots with bacteria (Morales et al., 1996). Studying morphological characters such as root system (Ayalew et al., 2015; Kabir et al., 2015) or developmental traits of different genotypes, including early growth rate, can also be evaluated in this method, which can provide the knowledge that can be useful to both breeders and growers.

Seedling vigor is one of the most important prerequisites for establishing successful stand of crop plants (Baloch et al., 2012), it affects the final yield (Rauf et al., 2007). The roots, known as 'the hidden half', play a main role in plant growth, they absorb water and nutrients from the soil, and can store them properly (Kutman et al., 2012; Smith and De Smet, 2012; Gaju et al., 2014), and they support the plants against lodging (Smith and De Smet, 2012). In wheat, there are two types of roots: the seminal roots and the nodal roots (Kirby, 2002). During germination, 3-6 seminal roots, in addition to the radicle, emerge. In the field, the seminal root system can reach more than $1 \mathrm{~m}$ deep and support the plant throughout its life cycle (Sylvester-Bradley et al., 2008). The nodal (crown or adventitious) roots, unlike the seminal roots, don't grow directly from the seed, but arise from the basal nodes of the stem and begin to extend when tillering starts (Kirby, 2002).

The root system of wheat is relatively complex, and because of the obstacles of selection for traditional root traits, architectural root properties that are expressed at early stages of crop development and determine the growth and functioning of the mature root system later in the season may be more suitable as selection criteria in crop improvement programs (Manschadi et al. 2006). These quantitative traits, called the root system architecture (RSA), including root number and length, tip and emergence angles, rooting width and depth among other traits, have been used to describe the root spatial configuration in soil (Pound et al., 2013; Atkinson et al., 2015).

However, measuring root traits in the field is very difficult since extraction of all intact roots from the soil is very time-consuming, expensive and requires much labor. Alternatively, many indoor methods have been applied, like using hydroponic culture (Ayalew et al., 2015; Kabir et al., 2015), gelfilled chambers (Manschadi et al., 2008; Christopher et al., 2013), sandfilled pots (Waines and Ehdaie, 2007; Hamada et al., 2012), soil-filled pots (Cao et al., 2014), clear pots (Richard et al., 2015), a germination paper-based 'pouch and wick' system (Atkinson et al., 2015), a 
paper-based 'cigar roll' system (Li et al., 2011; Bai et al., 2013) and soil-filled columns scanned by X-rays (Gregory et al., 2009). There is widespread evidence for genotypic variations in the root characteristics of many crop species (Ludlow and Muchow, 1990). In wheat, such traits include the depth of rooting, root elongation rate, root distribution at depth, xylem vessel diameter, and root to shoot dry matter ratio (Hoad et al. 2001; Manske and Vlek 2002; Manschadi et al., 2006).

The aim of our experiment was to study some morphological traits, namely root length, root number and shoot length at the early growing stage (5-10 days after emergence) in different wheat genotypes in hydroculture conditions. In the experiment 2 wheat varieties, a breeding line, a landrace and a spelt wheat variety were included assuming their good nutritional values (Abdel-Aal and Rabalski, 2008; Dotlačil et al., 2010).

\section{MATERIALS AND METHODS}

The experiment was conducted in the University of Debrecen, Research Centre of Nyíregyháza (Hungary) during the year 2014.

\section{Plant material}

Four winter wheat genotypes (Triticum aestivum L.), i.e. "Perbetei" (landrace), "1401 HK" (breeding line), "KG Bendegúz", "KG Kunhalom" (varieties) and a spelt wheat variety (Triticum spelta) "Franckenkorn" were tested under hydroponic culture conditions. Table 1 lists the main characteristics of the materials used in the experiment.

Table 1. The main characteristics of selected wheat genotypes in the experiment

\begin{tabular}{cccccc}
\hline Variety & "Perbetei" & "1401 HK" & "KG Bendegúz" & "KG & "Franckenkorn" \\
\hline Maturity & late & late & mid-early & mid-late & mid-late \\
1000 -seed Weight $(\mathrm{g})$ & 41 & 38 & 47 & 42 & 80 \\
Stem high $(\mathrm{cm})$ & high (125-135) & high (105-120) & Short (90-100) & high (110-120) & $145-165$ \\
Biomass weight & high & high & mid & mid & high \\
Yield t ha ${ }^{-1}$ & $3-4$ & $3-6$ & $7-9$ & $7-9$ & $2-5$ \\
Resistance to lodging & weak & weak & good & good & good \\
\hline
\end{tabular}

\section{Experimental setting conditions}

The seeds were soaked in 10 Liters of aerated tap water for $24 \mathrm{~h}$ in darkness at $22 \pm 2{ }^{\circ} \mathrm{C}$ (Policarpo et al., 2007), using an air pump. 10-day-old sprouted winter wheat cultures were produced in high purity without any microbial infection using $8 \mathrm{~g} \mathrm{l}^{-1}$ zeolite (sodium and calcium aluminium silicate in crystalline form) in tap water instead of disinfectants (Wang et al., 2012). After the swelling, the surplus water was removed. The fully imbibed grains were placed in transparent polystyrene boxes $(\mathrm{d}=5.5 \mathrm{~cm})$ (Figure 1), with different numbers of seeds depending on the thousand-seed-weight of genotypes („KG Bendegúz”: 105 pcs; „KG Kunhalom”: 130 pcs, „, Franckenkorn”: 100 pcs, „,1401 HK”: 130 pcs, „Perbetei”: 120 pcs) in order to create only one layer of seeds. After that, the seeds were kept in darkness at $22{ }^{\circ} \mathrm{C}$ for $48 \mathrm{~h}$ before they were cultured in plant growth chamber (Angelantoni CHL1500) under $12 \mathrm{~h}$ illumination, at $70 \%$ relative humidity and at $20^{\circ} \mathrm{C}$ for 10 days, because $20^{\circ} \mathrm{C}$ was found to be the best to prevent infections and to obtain shoots in high quality (Dziki et al., 2015). Water supply was made twice a day by spraying of distilled water to avoid excess water.
Figure 1. General view of wheat hydroculture experiment

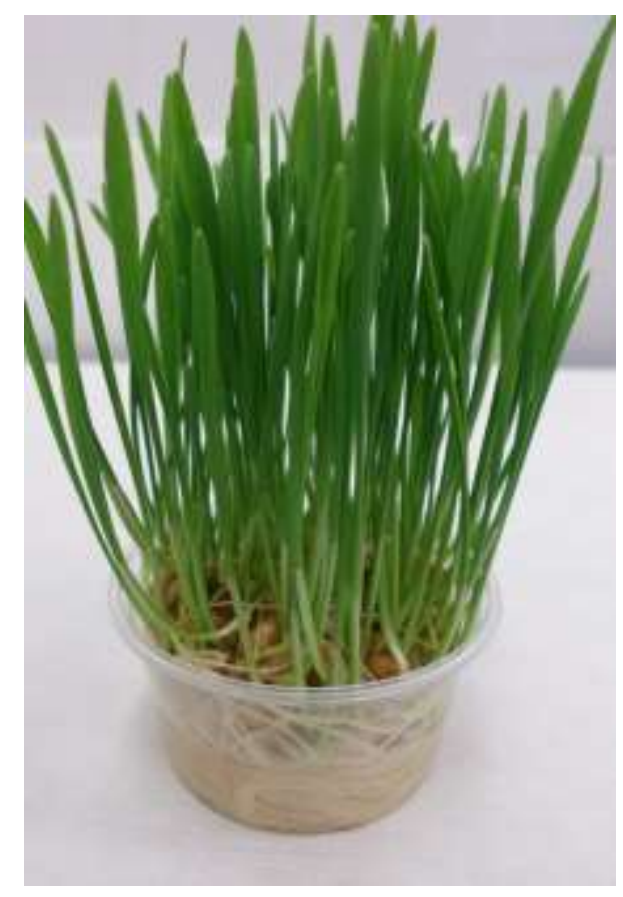




\section{Measurements and statistical analyses}

The experiment was initiated with 15 boxes per genotype, and three boxes were used for observation at four sampling times. Growth parameters (length of shoots, length and number of roots) were observed on $5^{\text {th }} ; 8^{\text {th }} ; 9^{\text {th }}$ and $10^{\text {th }}$ days: 10 seedlings per box were measured in three repetitions.

Data were analysed by ANOVA followed by Tukey-test $(\mathrm{P} \leq 0.05)$ using SPSS 26.0 software.

\section{RESULTS AND DISCUSSION}

\section{Root length}

Excessive growth of root system in hydroponic wheat culture is undesirable because fibrous roots require thorough processing before consumption. In addition, crowded rhizosphere creates circumstances which can enhance the growth of harmful microorganisms. Furthermore, the development of an extensive root system consumes a lot of energy and oxygen (Wetherell, 1988). Production of wheat seedlings for pressed juice also required shoot length up to $15 \mathrm{~cm}$ with a minimum of the root length (Koneva et al., 2018). Root system architecture of wheat shows large genetic variation among different ploidy levels, between domesticated and wild forms, and within each of the diploids, tetraploids and hexaploids (Manschadi et al., 2008; Ayalew et al., 2015). In our study we also observed significant differences in root development of wheat genotypes (Table 2).

Table 2. Root length (mm) of 10-day-old wheat seedlings

\begin{tabular}{|c|c|c|c|c|c|}
\hline Day & "Perbetei" & "1401 HK" & "KG Bendegúz" & "KG Kunhalom" & "Franckenkorn" \\
\hline 5 & $28.1^{\mathrm{c} 3}$ & $37.4^{\mathrm{c} 2}$ & $29.4^{\mathrm{c} 3}$ & $30.9^{\mathrm{c} 3}$ & $43.4^{\mathrm{d} 1}$ \\
\hline 8 & $56.8^{\mathrm{b} 3}$ & $69.2^{\mathrm{b} 2}$ & $50.1^{\mathrm{b} 3}$ & $84.3^{\mathrm{b} 1}$ & $96.1^{\mathrm{cl}}$ \\
\hline 9 & $72.9^{\mathrm{a} 3}$ & $105.0^{\mathrm{a} 12}$ & $68.4^{\mathrm{a} 3}$ & $93.8^{\mathrm{ab} 2}$ & $110.7^{\mathrm{b} 1}$ \\
\hline 10 & $60.9^{\mathrm{ab} 3}$ & $94.5^{\mathrm{a} 2}$ & $48.6^{\mathrm{b} 3}$ & $101.6^{\mathrm{a} 2}$ & $124.0^{\mathrm{a} 1}$ \\
\hline
\end{tabular}

- Same letters indicate no significant difference at .05 level among days within certain genotype.

- Same numbers indicate no significant difference at .05 level among genotypes within certain day.

The spelt wheat variety "Franckenkorn" could maintain higher root length throughout the experimental period. The extensive breeding line " 1401 HK" had significantly higher root length than the landrace variety "Perbetei" during the whole experiment. Both varieties "KG Bendegúz" and "KG Kunhalom" had a very similar root length on day 5 compared to "Perbetei", however, the roots of "KG Kunhalom" were significantly longer than both "KG Bendegúz" and "Perbetei" thereafter.

The root length of "Perbetei", "1401 HK" and "KG Bendegúz" reached their maximum on day 9 , whereas the rest showed the highest values of this trait at the last day of measurements (day 10). In their experiment, Wojciechowski et al. (2009) measured the root length of 7 different wheat Near-isogenic lines (NILs) (cv. Mercia) in gel chamber every second day until 12 days after germination. They reported that the different NILs had different root length through days, especially at day 10, where Rht-D1b line showed significantly less root length compared to Rht12 line. All studied lines showed continuously increasing root length over time
(Wojciechowski et al., 2009). Baloch et al. (2012) also reported that the seedlings of 16 different spring wheat genotypes had different root length after 10 days of applying distilled water, with the difference being significant for certain genotypes. Moreover, Wojciechowski et al. (2009) observed a relationship between root length and grain mass; i.e. longer roots developed from bigger seeds. In our experiment, correlation between root length and grain mass could not be detected (data not shown), probably because of the small differences in the 1000-seed-weight of the majority of genotypes (38-48 g). However, the longest roots developed from "Franckenkorn" seedlings, which have the highest grain mass (75-95 g).

\section{Root number}

On average, both "Perbetei" and "Franckenkorn" varieties could maintain higher root number compared to the other varieties, followed by "1401 HK", "KG Bendegúz" and "KG Kunhalom", respectively (Table $3)$.

Table 3. Root number of 10-day-old wheat seedlings

\begin{tabular}{|c|c|c|c|c|c|}
\hline Day & "Perbetei" & "1401 HK" & "KG Bendegúz" & "KG Kunhalom" & "Franckenkorn" \\
\hline 5 & $3.0^{\mathrm{b} 2}$ & $3.0^{\mathrm{b} 2}$ & $3.0^{\mathrm{b} 2}$ & $3.2^{\mathrm{c} 2}$ & $3.7^{\mathrm{b} 1}$ \\
\hline 8 & $4.7^{\mathrm{a} 1}$ & $4.5^{\mathrm{a} 12}$ & $4.4^{\mathrm{a} 12}$ & $4.0^{\mathrm{b} 2}$ & $4.4^{\mathrm{a} 12}$ \\
\hline 9 & $4.8^{\mathrm{a} 1}$ & $4.5^{\mathrm{a} 1}$ & $4.3^{\mathrm{a} 12}$ & $3.6^{\mathrm{bc} 2}$ & $4.8^{\mathrm{a} 1}$ \\
\hline 10 & $5.0^{\mathrm{a} 1}$ & $4.8^{\mathrm{a} 1}$ & $4.5^{\mathrm{a} 1}$ & $4.6^{\mathrm{a} 1}$ & $4.5^{\mathrm{a} 1}$ \\
\hline
\end{tabular}

- Same letters indicate no significant difference at .05 level among days within certain genotype.

- Same numbers indicate no significant difference at .05 level among genotypes within certain day. 
From a daily point of view, all varieties, except for "Franckenkorn", reached the highest root number by the end of the experiment and there were no significant differences in the root number between genotypes on $10^{\text {th }}$ day. Previously, the number of seminal roots was measured for 26 wheat cultivars representing some of the most widely grown varieties in Australia and 3 CIMMYT genotypes (Manschadi et al., 2008). The authors reported that the number of seminal roots varied between wheat genotypes. While Yitpi genotype developed consistently five seminal root axes, genotypes Petrie, EGA Wedgetail, and Babax were the genotypes with the lowest number of seminal roots. Moreover, cluster analysis of the seminal root number indicated that the wheat genotypes formed 4 discrete groups. Groups 1 and 2 consisted of eight genotypes each, while Groups 3 and 4 included nine and four cultivars, respectively. Wheat cultivars in Groups 1 and 2 exhibited a low number of seminal roots, whereas cultivars in Groups 3 and 4 comprised genotypes expressing a high number of seminal roots. Xie et al. (2017) made a cross between a bread wheat cultivar 'Forno' and spelt landrace 'Oberkulmer', and the subsequent F5 recombinant inbred lines (RILs) mapping population consisting of 226 lines was used in the study. The authors reported that there was a large variation in the $\mathrm{g}$ root system architecture (RSA), including root number, among the different RILs derived from Forno x Oberkulmer.

\section{Shoot length}

The extensive variety " 1401 HK" had the highest shoot length throughout the whole experiment, being significantly higher than the landrace variety "Perbetei" and both of the varieties "KG Bendegúz" and "KG Kunhalom", with an average shoot length of $133.8 \mathrm{~mm}$ at the end of experiment. "KG Bendegúz" had the lowest shoot length with an average of $103.4 \mathrm{~mm}$ on $10^{\text {th }}$ day (Table 4). In their experiment, Akbarimoghaddam et al. (2011) measured the shoot length of 6 wheat genotypes on $8^{\text {th }}$ day after germination; they found out that the different genotypes showed different shoot length, ranging from $15.61 \mathrm{~cm}$ to $22.11 \mathrm{~cm}$; however, these differences were insignificant (Akbarimoghaddam et al., 2011). The same conclusion was also reported (Baloch et al., 2012) with the differences being significant among the studied genotypes, and the shoot length of the 10-dayold seedlings ranging between 12.82 and $17.11 \mathrm{~cm}$.

Table 4. Shoot length (mm) of 10-day-old wheat seedlings

\begin{tabular}{|c|c|c|c|c|c|}
\hline Day & "Perbetei" & "1401 HK" & "KG Bendegúz" & "KG Kunhalom" & "Franckenkorn" \\
\hline 5 & $20.6^{\mathrm{c} 2}$ & $29.9^{\mathrm{cl}}$ & $20.0^{\mathrm{c} 2}$ & $18.4^{\mathrm{d} 2}$ & $27.0^{\mathrm{d} 1}$ \\
\hline 8 & $80.3^{\mathrm{b} 3}$ & $96.6^{\mathrm{b} 1}$ & $79.4^{\mathrm{b} 3}$ & $90.8^{\mathrm{c} 12}$ & $87.9^{\mathrm{c} 2}$ \\
\hline 9 & $107.3^{\mathrm{a} 2}$ & $129.6^{\mathrm{a}}$ & $107.0^{\mathrm{a} 2}$ & $104.1^{\mathrm{b} 2}$ & $110.0^{\mathrm{b} 2}$ \\
\hline 10 & $108.7^{\mathrm{a} 23}$ & $133.8^{\mathrm{a} 1}$ & $103.4^{\mathrm{a} 3}$ & $121.6^{\mathrm{a} 12}$ & $128.0^{\mathrm{a} 1}$ \\
\hline
\end{tabular}

- Same letters indicate no significant difference at .05 level among days within certain genotype.

- Same numbers indicate no significant difference at .05 level among genotypes within certain day.

\section{CONCLUSIONS}

It is very important to choose those winter wheat genotypes for hydroculture growing whose short roots or small root systems are genetically encoded, in addition to the development of an adequate shoot systems, since any treatment, which inhibited root growth, might reduce shoot growth (Wetherell, 1988). In this regard, "KG Bendegúz" cultivar and "Perbetei" landrace seemed to be the most suitable for aquaculture techniques. On the other hand, "1401 HK" breeding line can be the most suitable for the production of juice since the minimal required shoot length $(12 \mathrm{~cm})$ was achieved within the shortest period of time after sowing (9 days). This breeding line and "Franckenkorn" can also be suitable for production of "wheatgrass", because it is consumed without roots. Moreover, "Franckenkorn" showed high antioxidant capacity in Abdel-Aal and Rabalski studies (2008). Further research is needed to evaluate nutritional values of these genotypes.

\section{ACKNOWLEDGEMENTS}

Our research was carried out in the scope of the (AGR_PIAC_13-1-2013-0002) project "Production of Adaptive Winter Wheat Lines with Excellent Milling Parameters".

\section{REFERENCES}

Abdel-Aal, E.S.M.-Rabalski, I. (2008): Bioactive compounds and their antioxidant capacity in selected primitive and modern wheat species. The Open Agriculture Journal. 2: 7-14.

Ashraf, M.A.-Ashraf, M. (2016): Growth stage-based modulation in physiological and biochemical attributes of two genetically diverse wheat (Triticum aestivum $\mathrm{L}$.) cultivars grown in salinized hydroponic culture. Environ Sci Pollut Res. 23: 6227-6243. DOI: $10.1007 / \mathrm{s} 11356-015-5840-5$

Atkinson, J.A.-Wingen, L.U.-Griffiths, M.-Pound, M.P.-Gaju, O.Foulkes, M.J., Le Gouis, J.-Griffiths, S.-Bennett, M.J.-King, J.Wells, D.M. (2015): Phenotyping pipeline reveals major 
seedling root growth QTL in hexaploid wheat. Journal of Experimental Botany. 66(8): 2283-2292.

Ayalew, H.-Ma, X.-Yan, G. (2015): Screening wheat (Triticum spp.) genotypes for root length under contrasting water regimes: potential sources of variability for drought resistance breeding. Journal of Agronomy and Crop Science. 201: 189-194.

Bai, C.-Liang, Y.-Hawkesford, M.J. (2013): Identification of QTLs associated with seedling root traits and their correlation with plant height in wheat. Journal of Experimental Botany. 64: 1745-1753.

Baloch, M.J.-Dunwell, J.-Khakwani, A.A.-Dennet, M.-Jatoi, W.A.-Channa, S.A. (2012): Assessment of wheat cultivars for drought tolerance via osmotic stress impose at early seedling growth stages. J. Agric. Res. 50(3): 299-310.

Benincasa, P.-Falcinelli, B.-Lutts, S.-Stagnari, F.-Galieni, A. (2019): Sprouted Grains: A Comprehensive Review. Nutrients. 11: 421. doi:10.3390/nu11020421

Cao, P.-Ren, Y.-Zhang, K.-Teng, W.-Zhao, X.-Dong, Z.-Liu, X.Qin, H.-Li, Z.-Wang, D.-Tong, Y. (2014): Further genetic analysis of a major quantitative trait locus controlling root length and related traits in common wheat. Molecular breeding. 33(4): 975-985.

Christopher, J.-Christopher, M.-Jennings, R.-Jones, S.-Fletcher, S.Borrell, A.-Manschadi, A.M.-Jordan, D.-Mace, E.-Hammer, G. (2013): QTL for root angle and number in a population developed from bread wheats (Triticum aestivum) with contrasting adaptation to water-limited environments. Theoretical and Applied Genetics. 126(6): 1563-1574.

Dilday, R.H.-Mgonja, M.A.-Amonsilpam, S.A.-Collins, F.C.Wells, B.R. (1990): Plant height vs. mesocotyl and coleoptile elongation in rice: Linkage or pleiotropism? Crop Sci. 30: 815818.

Dotlačil, L.-Stehno, J.H.-Dvořaček, V.-Bradová, J.-Leišsová, L. (2010): How can wheat landraces contribute to present breeding? Czech J. Genet. Plant Breed. 46 (Special Issue): 70-74.

Dziki, D.-Gawlik-Dziki, U.-Kordowska-Wiater, M.-Domań-Pytka, M. (2015): Influence of elicitation and germination conditions on biological activity of wheat sprouts. Journal of Chemistry. doi: dx.doi.org/10.1155/2015/649709.

Gaju, O.-Allard, V.-Martre, P.-Le Gouis, J.-Moreau, D.-Bogard, M.-Hubbart, S.-Foulkes, M.J. (2014): Nitrogen partitioning and remobilization in relation to leaf senescence, grain yield and grain nitrogen concentration in wheat cultivars. Field Crops Research. 155: 213-223.

Gregory, P.J.-Bengough, A.G.-Grinev, D.-Schmidt, S.-Thomas, W.B.T.-Wojciechowski, T.-Young, I.M. (2009): Root phenomics of crops: opportunities and challenges. Functional Plant Biology. 36(11): 922-929.

Hamada, A.-Nitta, M.-Nasuda, S.-Kato, K.-Fujita, M.-Matsunaka, H.-Okumoto, Y. (2012): Novel QTLs for growth angle of seminal roots in wheat (Triticum aestivum L.). Plant and Soil. 354(1-2): 395-405.

Hoad, S.P.-Russell, G.-Lucas, M.E.-Bingham, I.J. (2001): The management of wheat, barley, and oat root systems. Adv Agron. 74: 193-246.

Kabir, M.R.-Liu, G.-Guan, P.-Wang, F.-Khan, A.A.-Ni, Z.-Yao, Y.-Hu, Z.-Xin, M.-Peng, H.-Sun, Q. (2015): Mapping QTLs associated with root traits using two different populations in wheat (Triticum aestivum L.). Euphytica. 206(1): 175-190.

Kirby, E.J.M. (2002): Botany of the wheat plant. In: Curtis BC, Rajaram S, Gomez Macpherson $\mathrm{H}$, eds. Bread wheat improvement and production. Rome: Food and Agriculture Organization of the United Nations, 19-38.

Koneva, M.S.-Rudenko, O.V.-Usatikov, S.V.-Bugaets, N.A.Tereschenko, I.V. (2018): Implicitly defined criteria for vector optimization in technological process of hydroponic germination of wheat grai. International Conference Information Technologies in Business and Industry, 2018. IOP Conf. Series: journal of Physics: Conf. Series 1015: 032019. DOI: 10.1088/1742-6596/1015/3/032019

Kulkarni, S.D.-Acharya, R.-Rajurkar, N.S.-Reddy, A.V.R. (2007): Evaluation of bioaccessibility of some essential elements from wheatgrass (Triticum aestivum L.) by in vitro digestion method. Food Chemistry. 103(2007): 681-688. doi: 10.1016/j.foodchem.2006.07.057

Kulkarni, S.D.-Tilak, J.C.R.-Acharya, R.-Rajurkar, N.S.Devasagayam, T.P.A.-Reddy, A.V.R. (2006): Evaluation of the Antioxidant Activity of Wheatgrass (Triticum aestivum L.) as a Function of Growth under Different Conditions. Phytother. Res. 20: 218-227. DOI: 10.1002/ptr.1838.

Kutman, U.B.-Kutman, B.Y.-Ceylan, Y.-Ova, E.A.-Cakmak, I. (2012): Contributions of root uptake and remobilization to grain zinc accumulation in wheat depending on post-anthesis zinc availability and nitrogen nutrition. Plant and Soil. 361: 177-187.

Li, P.-Chen, J.-Wu, P.-Zhang, J.-Chu, C.-See, D.-Brown-Guedira, G.-Zemetra, R.-Souza, E. (2011): Quantitative Trait Loci Analysis for the Effect of Rht-B1 Dwarfing Gene on Coleoptile Length and Seedling Root Length and Number of Bread Wheat. Crop Science. 51(6): 2561-2568.

Ludlow, M.M.-Muchow, R.C. (1990): A critical evaluation of traits for improving crop yields in water-limited environments. Adv Agron. 43: 107-153.

Manschadi, A.M.-Christopher, J.-deVoil, P.-Hammer, G.L. (2006): The role of root architectural traits in adaptation of wheat to water-limited environments. Funct Plant Biol. 33: 823-837.

Manschadi, A.M.-Hammer, G.L.-Christopher, J.T.-deVoil, P. (2008): Genotypic variation in seedling root architectural traits and implications for drought adaptation in wheat (Triticum aestivum L.). Plant and Soil. 303: 115-129.

Manske, G.G.B.-Vlek, P.L.G. (2002): Root architecture - wheat as a model plant. In: Waisel Y, Eshel A, Kafkafi U (eds) Plant roots: the hidden half. Marcel Dekker, New York, USA, pp 249-259.

Morales, A.-Garland, J.L.-Lim, D.V. (1996): Survival of potentially pathogenic human-associated bacteria in the rhizosphere of hydroponically grown wheat. FEMS Microbiology Ecology. (20): 155-162.

Morgan, J.M.-Hare, R.A.-Fletcher, R.J. (1986): Genetic variation in osmo-regulation in bread and durum wheat and its relationship to grain yield in a range of field environments. Aust. J. Agric. Res. 37: 449-457.

Ndaru, P.H.-Huda, A.N.-Marjuki-Prasetyo, R.D.-Shofiatun, U.Nuningtyas, Y.F.-Ndaru, A.N. (2020): Providing High Quality Forages with Hydroponic Fodder System. IOP Conf. Series: Earth and Environmental Science. 478: 012054. doi: 10.1088/1755-1315/478/1/012054.

Pound, M.P.-French, A.P.-Atkinson, J.A.-Wells, D.M.-Bennett, M.J.-Pridmore, T. (2013): RootNav: navigating images of complex root architectures. Plant Physiology. 162: 1802-1814.

Rauf, M.-Munir, M.-Ul-Hassan, M.-Ahmed, M.-Afzal, M. (2007): Performance of wheat genotypes under osmotic stress at germination and early seedling growth stage. Afr. J. Biotechnol. 8: 971-975. 
Richard, C.A.I.-Hickey, L.T.-Fletcher, S.-Jennings, R.-Chenu, K.Christopher, J.T. (2015): High-throughput phenotyping of seminal root traits in wheat. Plant Methods. 11: 13.

Rizwan, M.-Meunier, J-D.-Davidian, J-C.-Pokrovsky, O.S.-Bovet, N.-Keller, C. (2016): Silicon alleviates Cd stress of wheat seedlings (Triticum turgidum L. cv. Claudio) grown in hydroponics. Environ Sci Pollut Res. 23: 1414-1427. DOI 10.1007/s11356-015-5351-4

Smith, S.-de Smet, I. (2012): Root system architecture: insights from Arabidopsis and cereal crops. Philosophical Transactions of the Royal Society B: Biological Sciences. 367: 1441-1452.
Sylvester-Bradley, R.-Berry, P.-Blake, J.-Kindred, D.-Spink, J.Bingham, I.-McVittie, J.-Foulkes, J.-Edwards, C.-Dodgson, G.-Boys, E. (2008): The wheat growth guide. HGCA: London.

Waines, J.G.-Ehdaie, B. (2007): Domestication and crop physiology: roots of Green-Revolution wheat. Annals of Botany. 100: 991998.

Wetherell, D. (1988): Hormonal regulation of wheat growth during hydroponic culture. NASA Technical Reports Server (NTRS). https://ntrs.nasa.gov/archive/nasa/casi.ntrs.nasa.gov/198900047 96.pdf 